\title{
Canadian Economists' Citation and Publication Records*
}

\author{
HERBERT G. GRUBEL†
}

\begin{abstract}
This paper uses the Social Science Citation Index to count the number of citations received and publications made by all economists teaching at Canadian universities in 1975.

It is shown that the top decile of individuals received 72 per cent of all citations and 50 per cent received none. The University of British Columbia and Simon Fraser University departments of economics have the highest and second-highest average citation counts of all Canadian universities, respectively. The age-profile of citations, self-citation propensities and the journals of publication are analysed from a sub-sample of data
\end{abstract}

\section{RESUMÉ}

Cet article utilise le Social Science Citation Index pour relever le nombre de citations reçues et de publications au crédit de tous les économistes qui enseignaient dans les universités canadiennes durant l'année 1975.

Il est démontré que le décile supérieur d'individus a reçu 72 pour cent de toutes les citations et que 50 pour cent en ont recu aucune. Les départments d'économique des universités de la Colombie-Britanique et Simon Fraser ont respectivement le plus grand et le deuxième plus grand nombres moyens de citations de toutes les universités canadiennes. L'aspect temporel des citations, les propensions d̀ l'auto-citation et les revues de publication sont analisés à l'aide d'un sous-échantillon de données.

Since 1974, the publication of the Social Science Citation Index ${ }^{1}$ has made it practical to use citation and publication counts for individual economists as supplementary information in decisions about hiring, promotion and tenure of professors, the allocation of resources among and to university departments and the choice of university departments for study or work, much as has been done for many years in the physical sciences. One problem in the use of these counts for individuals is the absence of any information

\footnotetext{
* The work on this paper was supported by grant S75-1194 from the Canada Council. I have received helpful comments on an earlier draft by P. Copes and J. Vanderkamp.

$\dagger$ Department of Economics, Simon Fraser University.
} 
about such counts for a large number of social scientists by which individual records can be put into perspective. It is the main purpose of this paper to provide such a standard through the analysis of the distribution of publication and citation counts for all Canadian academic economists and subsets of economists in individual departments of economics. However, the data also provide some useful information about the relative research productivity of individual university departments as of the middle of the 1970's. The paper also provides basic information which can be used in the future to study trends in publication and citation records, to compare the records of Canadian economists with those of other subsets drawn from different countries or areas of specialization and to compare economists with groups of scientists from other fields.

In Part I of this paper the purpose and merit of publication and citation studies are considered in the light of similar work in the natural sciences that has been going on for over a decade. Part II discusses the nature and sources of the data underlying this study. Part III considers the characteristics of the total population. In Part IV, the records of individual Canadian university departments of economics are presented. The age and other characteristics of citations are studied in Part V. Part VI presents and analyses the list of journals in which Canadian economists publish. Individuals with the largest number of citations and publications are identified in Part VII. The paper closes with a summary and some implications of the analysis.

\section{THE PURPOSE AND MERIT OF PUBLICATION AND CITATION COUNTS}

The popularity of studying publication and citation counts of individual scientists and institutions is evidenced by the large number of publications on this subject, a selection of which is shown in the attached bibliography. However, popularity is an unreliable guide to scientific merit and the field has a number of sceptics and critics. (See Hanson and Weisbrod, (1972) and Comfort, (1970)). Anyone exposed to, or involved in, academic politics knows all the arguments about the merit of quality against quantity of publications. The journals Science and Nature contain a number of letters to the editor in which scientists point out why citation counting may be an imperfect method for assessing a scientist's productivity or the importance of his contribution to knowledge. ${ }^{2}$

Whatever may be the appeal of theoretical arguments about the merit of citation and publication counts, basically it is an empirical question whether they are a useful measure of scientists' contributions to knowledge and the prestige and influence derived from them. Several studies have attempted to answer this empirical question. Clark (1957) conducted a survey of psychologists and on the basis of about 1,200 replies constructed a ranking of U.S. psychologists according to their peers' informal evaluation of the merit of their work and the resultant prestige and influence. Clark then correlated this ranking with rankings based on objective measures of productivity and prestige, such as membership in professional associations, number of publications, listing in Who's Who, editorship of professional journals and citations. He found the greatest correlation of informal peer judgements with the number of citations $(R=.67)$. In another study, Hagstrom (1971) attempted to explain the well-known Cartter (1966) ratings of U.S. graduate schools, which are based on surveys of a relatively large number of department chairmen in every field. Like Clark, the author used many other objectively measurable characteristics that can be expected to reflect or determine quality of university departments on a priori grounds. Of the about 12 such characteristics analysed, both the number of publications 
and citations dominate the rest, but as a result of a multiple regression result the author concludes "Citations to published work are a better predictor of department prestige than is quantity of articles published."(Hagstrom, 1971, p. 373). ${ }^{3}$

\section{The Use of Citation Counts}

Students and potential users of citation counts apparently have been convinced by the available evidence that the technique represents a low-cost and sufficiently reliable technique to find "major uses in decisions at the level of national science policy, as an adjunct to the peer-review process, and in evaluating the performance of individual scientists". (Wade, 1975, p. 429). The author of this quotation notes that the U.S. National Science Foundation already uses citation counts in its decisions about the allocation of research funds in chemistry, especially to aid in reducing awards to individuals who write good proposals but have a poor record of scientific achievement and increasing awards to those who are not good writers of proposals but have a superior record of citations.

\section{SOURCES OF DATA}

The study was made feasible by the availability of the annual volumes of the Social Science Citation Index (SSCI) for the years 1970-76. It is produced by the private Institute for Scientific Information (ISI) of Philadelphia which manipulates electronically citation information contained in hundreds of journals from the social sciences published in many countries. Two ISI publications are relevant for this study. First, an alphabetic listing of authors shows their journal publications during a given year. ${ }^{4}$ Book reviews are identified and are excluded from the counts prepared in this study. Papers with multiple authors are identifiable for each author. They are counted as one publication for each of the multiple authors.

Second, an alphabetical listing shows for every author the citations that were made to his works, including the name and publication in which the citation appeared. Importantly, while the publication counts cover only journals, the citations from journals cover all publications by the individuals, including books, edited works, government reports, mimeographed papers and dissertations. However, unfortunately citations to papers with inultiple authors are attributed only to the first listed author. This fact introduces a bias of unknown but possibly serious magnitude into the ranking of individuals. In the ranking of departments, on the other hand, there should be no serious bias introduced since the incidence of multiple authorship can reasonably be assumed to be distributed normally across departments.

The collection and processing of the data was subject to a more than normal margin of error because the clerical work in searching and transferring the information is especially tedious. Also, there are sources of error resulting from sloppy citation habits, such as the use of only one or wrong initials, and from the fact that there are some individuals that have the same names and initials. Double-checking by two different clerks of citations to individuals who in the first run showed up as having had more than 3 citations during the period was used in an attempt to minimize clerical errors.

The number of social science journals fully surveyed by the SSCI is over 1,000. Furthermore, references to social scientists found in over 2,000 natural science journals are included. The journals cover those published in the United States and Canada as well as 
many other countries. Indicative of the broad coverage is the fact that the 1,502 publications by Canadians appeared in 233 different journals (see Section VI below).

The population of Canadian economists was defined as consisting of individuals who were listed on the faculties of the universities shown in Table 5 according to the Commonwealth Universities Yearbook, 1976, giving the status as of the middle of 1975. Part-time lecturers and teaching assistants were excluded.

\section{CHARACTERISTICS OF THE TOTAL POPULATION}

Table 1 shows the frequency distribution of citations and articles for the entire population of 768 Canadian academic economists, which in turn is summarized in Table 2 by the percentages by deciles, both absolute and cumulative. As can be seen, the top decile of Canadian academic economists accounts for 72.3 and 43.7 per cent of all citations and articles, respectively; while 50 per cent have not been cited or have not published at all. These results are similar to those found by Cole and Cole (1972) for physicists, though in all studies of this type it is difficult to obtain a list of names representing the full population, since those who do not publish or are not cited do not appear in the literature. ${ }^{5}$

However, the frequency distributions of Canadian academic economists' citation and publication counts do not conform with Lotka's Law (Lotka, 1926), which has been found to hold in many scientific disciplines. The law says that $N=K / n^{2}$, where $K$ is the number of people publishing one article, $\mathrm{n}$ is the number of articles published by each of the individuals numbered $\mathrm{N}$. Thus, according to Lotka's Law, the fact that 114 Canadian economists have published one article (see Table 1), implies that 28.5 should have published two, 13 published three, about 8 published four, etc. In reality, as can be seen from Table 1, the distribution is much less skewed. The same conclusions hold for the frequency distribution of citations. Perhaps this result is due to the fact that the present sample consists of academics with high publication propensities while Lotka's Law applies to professionals in all types of employment. Very likely, the results simply invalidate Lotka's Law, which has no theoretical foundation at all.

\section{Canadian and Global Performance}

In an attempt to put the population of Canadian economists' records into a global perspective, a world-wide population of international trade economists was defined by obtaining 2,813 names of individuals who published at least one article that entered category 400 in the Journal of Economic Literature during the period 1970-76 and by comparing them with the 1,158 names of persons who identified themselves as specialists in international economics (catagory 400) in the American Economics Association Handbook (1974). Of those 1,158 specialists only 371 , or 32 per cent showed up as having published according to the list derived from the Journal of Economic Literature. Since about 50 per cent of all Canadians published at least one paper, the comparison with the population of international economics specialists favors Canadian economists. However, the results of this comparison are probably biased since the number of journals surveyed by the Journal of Economic Literature is much smaller than that included in the SSCI.

For the population of international trade economists who have published at least three articles according to the Journal of Economic Literature $(\mathrm{N}=455)$, citations were counted for the period 1970-76 and analyzed in Grubel (1980). The list is headed by P.A. 
31 Canadian Economists' Citation and Publication Records

Table 1

Frequency Distribution of the Number of Citations

and Articles, $1970-76$

\begin{tabular}{|c|c|c|c|}
\hline \multicolumn{4}{|c|}{ Absolute Numbers of } \\
\hline Citations & Persons & Publications & Persons \\
\hline Above 200 & 3 & 17 & 1 \\
\hline $199-100$ & 15 & 15 & 2 \\
\hline $99-90$ & 3 & 14 & 1 \\
\hline $89-80$ & 5 & 13 & 3 \\
\hline $79-70$ & 4 & 12 & 4 \\
\hline $69-60$ & 5 & 11 & 8 \\
\hline $59-50$ & 6 & 10 & 7 \\
\hline $49-40$ & 10 & 9 & 9 \\
\hline $39-30$ & 16 & 8 & 4 \\
\hline $29-20$ & 34 & 7 & 15 \\
\hline 19 & 3 & 6 & 25 \\
\hline 18 & 8 & 5 & 37 \\
\hline 17 & 5 & 4 & 40 \\
\hline 16 & 4 & 3 & 60 \\
\hline 15 & 5 & 2 & 90 \\
\hline 14 & 7 & 1 & 114 \\
\hline 13 & 10 & 0 & 348 \\
\hline 12 & 6 & & $\overline{768}$ \\
\hline 11 & 11 & & \\
\hline 10 & 12 & & \\
\hline 9 & 10 & & \\
\hline 8 & 11 & & \\
\hline 7 & 27 & & \\
\hline 6. & 13 & & \\
\hline 5 & 20 & & \\
\hline$\dot{4}$ & 14 & & \\
\hline 3 & 30 & & \\
\hline 2 & 44 & & \\
\hline 1 & 71 & & \\
\hline 0 & 356 & & \\
\hline & $\overline{768}$ & & \\
\hline
\end{tabular}

Source: Compiled by the author from citations in annual volumes of the Social Science Citation Index, 1970-76. Names of persons from Commonwea1th Universities Handbook, 1976.

Samuelson and H.G. Johnson with 2,898 and 1,498 citations, respectively. These two men are followed by five individuals with 613-682 citations. Canadian economists among the top 70 show up in 15 th place, 37 th, 53 rd, 67 th and 69 th. Since Canada's population is about 10 per cent of that of the United States, random geographic distribution of a combined U.S.-Canada population with equal productivity should have produced the observed fact that about 10 per cent should be Canadian. While these results are sensitive to the field studied and the cut-off point chosen on the list (among the top 60 there are only 3 Canadians and none among the top 14), the results reported here may be interpreted tentatively as suggesting an approximate equality in the productivity of U.S. and Canadian academic economists. 


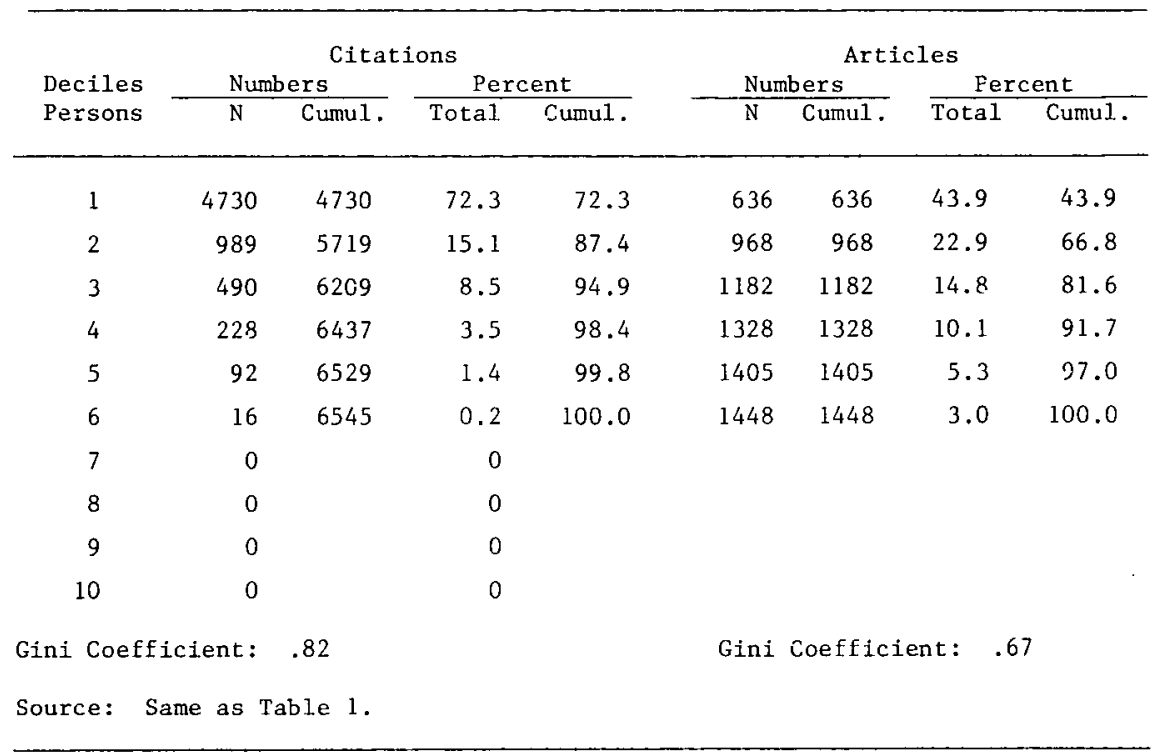

\section{The Cause of the Skewed Distribution}

Generally, the extreme skewness of the frequency distribution of publication and citation counts represents a puzzle, since presumably practically all economists in the sample have a Ph.D. and therefore the basic qualifications to be contributors to the stock of knowledge through publications. Furthermore, all studies of single, measurable human abilities and characteristics show them to be normally distributed. Allison and Stewart (1974) analyze this question theoretically and empirically. On the theoretical level, they cite work which suggests that while single skills are distributed normally, combinations of skills are required to perform complicated tasks and the combinations determine productivity multiplicatively. (See Shockley (1957) and Aitchison and Brown (1957)). Since the publication of scientific work involves a more complicated task and requires the combination of a large number of specific skills and characteristics than does study leading to a Ph.D., the observed skewness theoretically is consistent with other empirical knowledge.

In addition to the purely theoretical explanation, Allison and Stewart also postulate that the reward structure of science reinforces the skewness of the distribution through what they call a process of cumulative advantage. This process is reflected in the fact that the award of resources, the invitation to conferences, journal editorships, etc., tend to favor productive individuals, further adding to their differential productivity. An empirical analysis of the Gini coefficients of scientists from several different disciplines in certain age-cohorts determined by the time since receipt of the Ph.D. showed that the degree of inequality increases through time. ${ }^{6}$ 


\section{ANALYSIS OF DEPARTMENT STATISTICS}

Table 3 presents data on citation and publication counts averaged by university departments, according to economists' affiliation as of the middle of 1975 . The first column shows the number of faculty in each department and the following columns show for each department the total, mean, variance, Gini-coefficient (for faculties with more than 21 members only) and rank by average, first for citations and then for publications. The correlation coefficient $\left(R^{2}\right)$ for the citations and publications is .65

As is well known, the mean is often a misleading measure of the average of a distribution, especially if it is as skewed as the one for all economists noted above. To deal with the problems inherent in the case of the mean, Table 3 contains the variance and Gini coefficients characterizing the distribution for each department. However, the biases introduced by the use of the mean are apparent much more directly through the data contained in Table 4, the number of citations received by the median and 80th percentile member of each faculty. Because the median was zero for many departments for reasons obvious from the fact that about 50 percent of all economists have zero citations, and because both the medians and percentile measures are not suitable measures in small departments, the list in Table 3 contains data on only the top 12 departments, though the rankings in each column are based on the full population of departments.

The most notable fact apparent from Table 4 is that the top 12 universities by the mean are also the top 12 by the 80th percentile, while by the median the University of Ottawa and Dalhousie University move from the top 12 into 13-18th rank. These two universities are replaced by the Royal Military College in 9th place and Mt. St. Vincent University in 10-11th rank. The fact that the latter 2 departments have faculties of 8 and 2 members only shows one of the difficulties in using the median as a measure of the average.

By all three measures the University of British Columbia heads the list consistently, while other universities show some changes in ranking. Most notable differences in the ranks by mean and median are that the University of Toronto moved from its 6th place by the mean rank, into a tie for second place with Simon Fraser University in the median rank and that Carleton University and University of Montreal, respectively, moved up from 8 th to 4 th and 12 th to 5 th. Lowering of rank finds Queens University drop from 3rd place by the mean to 7th by the median and the University of Western Ontario from 4 th to 6 th. The rankings by means and 80 th percentile are remarkably consistent, with a move up of 3 by the University of Ottawa and the University of Montreal and a move down of 2 by Simon Fraser University and Queens University.

The main message implicit in Table 4 seems to be that the leading departments are characterized by both the presence of "stars", giving rise to large means and of a substantial proportion of faculty with high citation counts resulting in large medians and 80th percentile values. The University of British Columbia's position of leadership is strengthened not only by its consistent top ranking by all these measures of average, but also the absolute number of citations by all three measures in relation to those of any other Canadian university.

Returning to Table 3 , it is worth noting the last column which shows the difference between the university's rank on the citation and publication counts. The interpretation of these figures is that large positive numbers indicate that in the future the department's ranking by citation counts is likely to improve and large negative numbers indicate the 


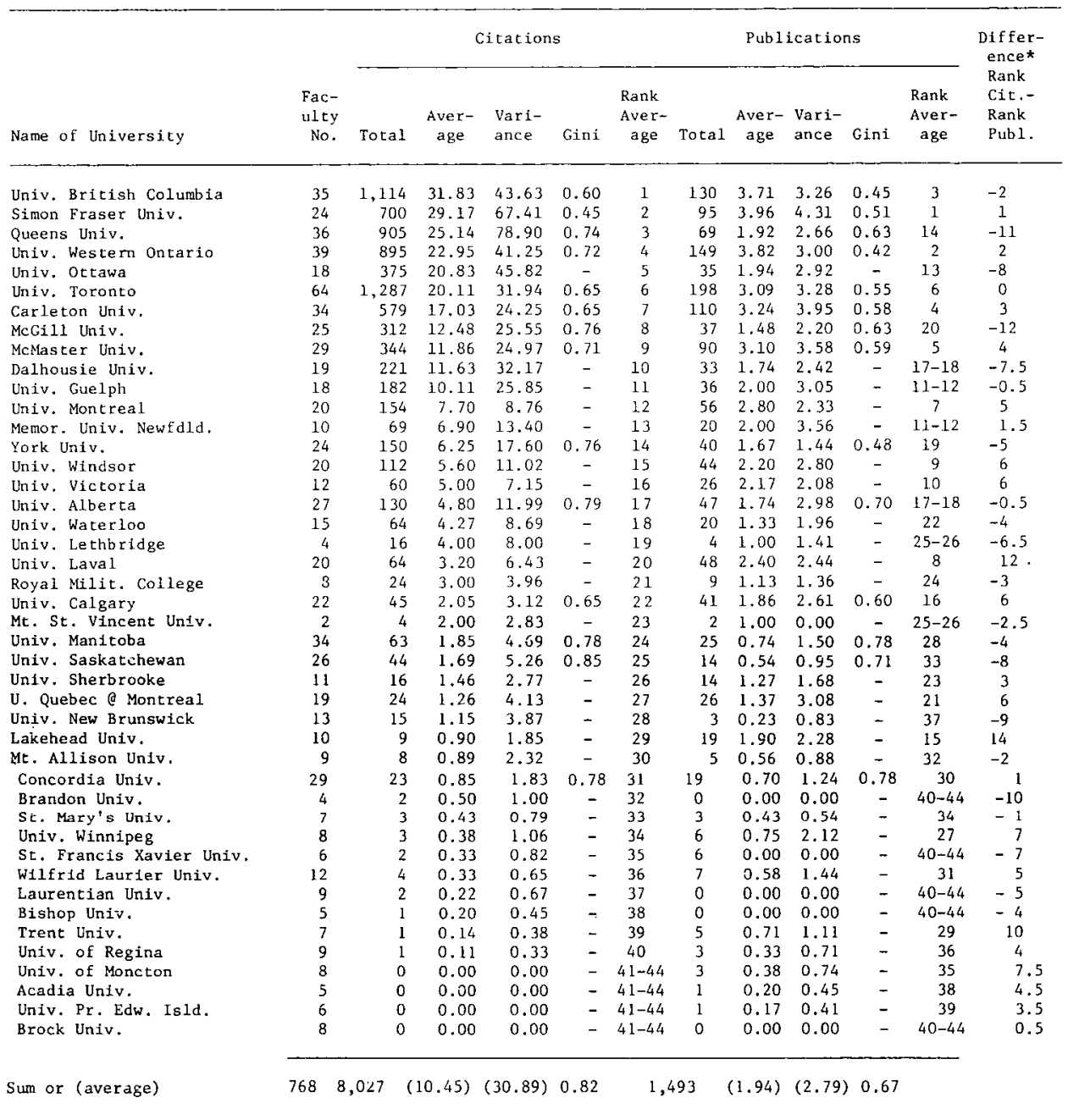

Source: Same as Table 1 .

Note: $\star$ Note on last column: In case of ties, difference is between midpoints.

opposite. This interpretation is based on the fact documented below, that publications lead to citations with a lag, so that high publication ranks may at a later time lead to high citation ranks and vice versa.

\section{CHARACTERISTICS OF CITATIONS}

A stratified sample of $1 / 7$ th of all citations to the writings of Canadian economists was analyzed to establish facts in three areas: the distribution of citations between different forms of publications, their age profiles, and the frequency of self-citations. 


\begin{tabular}{lcc|cc|cc}
\hline Department & Mean & Rank & Median & Rank & $\begin{array}{c}80 \text { th } \\
\text { Percentile }\end{array}$ & Rank \\
\hline Univ. British Columbia & 31.9 & 1 & 11 & 1 & 75 & 1 \\
Simon Fraser Univ. & 29.2 & 2 & 9 & $2-3$ & 34 & 4 \\
Queens Univ. & 25.1 & 3 & 4 & 7 & 29.5 & 5 \\
Univ. West. Ontario & 23.0 & 4 & 5 & 6 & 36 & 3 \\
Univ. Ottawa & 20.8 & 5 & 1 & $13-18$ & 41 & 2 \\
Univ. Toronto & 20.1 & 6 & 9 & $2-3$ & 23 & $6-7$ \\
Carleton Univ. & 17.0 & 7 & 8 & 4 & 23 & $6-7$ \\
McGill Univ. & 12.5 & 8 & 2 & $10-11$ & 16.5 & 8 \\
McMaster Univ. & 11.9 & 9 & 3.5 & 8 & 14 & 10 \\
Dalhousie Univ. & 11.6 & 10 & 1 & $13-18$ & 7.5 & 11 \\
Guelph Univ. & 10.1 & 11 & 1.5 & 12 & 7 & 12 \\
Univ. Montreal & 7.7 & 12 & 5.5 & 5 & 16 & 9 \\
\hline
\end{tabular}

Source: Same as Table 1.

Note: Ranks are based on full population of universities.

Table 5 shows that of the 1152 citations originating in journals 826 , or about 72 per cent, made reference to journal articles or mimeographed discussion papers and 326 , or about 28 per cent, to books, theses, government reports or anthologies. Unfortunately, the basic distribution of total writings published in these two different categories is not known so that no inferences can be made about the relative intensity of citations to journal and other forms of publications. However, the data do suggest that the publication counts shown above for individuals and departments are incomplete because they cover only journals. If there are different propensities of individuals to publish in forms other than journal articles, therefore, the rankings are biased. No attempts were made to correct for these biases. It could be that they account for some of the pronounced differences in rankings among university departments made according to citations and publications shown in Table 3.

The age-profile of citations is also shown in Table 5, using as the basic statistic the number of years between publication of the cited work and citations to it. A lag of zero years arises in cases of simultaneous publication years and when the reference is to work "to be published". As can be seen from Table 5, journal articles tend to be cited with a somewhat greater lag after publication than books, etc. This is a surprising result which may be explained by the fact that the latter forms of publication tend to have a longer 
Table 5

Age Profile of Citations of Canadian Economists

\begin{tabular}{|c|c|c|c|c|c|c|}
\hline \multirow{2}{*}{$\begin{array}{l}\text { Number of Years } \\
\text { Between Publication } \\
\text { and Citation }\end{array}$} & \multicolumn{3}{|c|}{$\begin{array}{c}\text { Journals } \\
\text { Discussion Papers }\end{array}$} & \multicolumn{3}{|c|}{$\begin{array}{l}\text { Books, Theses, cuts. } \\
\text { Reports, Anthologies }\end{array}$} \\
\hline & $\mathrm{N}$ & $\%$ & Cum.\% & $\mathrm{N}$ & $\%$ & Cum.\% \\
\hline 0 & 30 & 3.6 & 3.6 & 17 & 5.2 & 5.2 \\
\hline 1 & 89 & 10.8 & 14.4 & 54 & 16.6 & 21.8 \\
\hline 2 & 107 & 13.0 & 27.4 & 66 & 20.2 & 42.0 \\
\hline 3 & 141 & 17.1 & 44.5 & 40 & 12.3 & 54.3 \\
\hline 4 & 107 & 13.0 & 57.5 & 38 & 11.7 & 66.0 \\
\hline 5 & 76 & 9.2 & 66.7 & 19 & 5.8 & 71.8 \\
\hline 6 & 42 & 5.1 & 71.8 & 10 & 3.1 & 74.9 \\
\hline 7 & 46 & 5.6 & 77.4 & 13 & 4.0 & 78.9 \\
\hline 8 & 31 & 3.8 & 81.2 & 9 & 2.8 & 81.7 \\
\hline 9 & 39 & 4.7 & 85.9 & 11 & 3.4 & 85.1 \\
\hline 10 & 38 & 4.6 & 90.5 & 13 & 4.0 & 89.1 \\
\hline 11 & 10 & 1.2 & 91.7 & 14 & 4.3 & 93.4 \\
\hline 12 & 5 & 0.6 & 92.3 & 2 & 0.6 & 94.0 \\
\hline 13 & 3 & 0.4 & 92.7 & 5 & 1.5 & 95.5 \\
\hline 14 & 10 & 1.2 & 93.9 & 2 & 0.6 & 91.1 \\
\hline 15 & 7 & 0.8 & 94.7 & - & - & - \\
\hline 16 & 17 & 2.1 & 96.8 & 7 & 2.1 & 98.2 \\
\hline 17 & 5 & 0.6 & 97.4 & 2 & 0.6 & 98.8 \\
\hline 18 & 9 & 1.1 & 98.5 & - & - & - \\
\hline 19 & 6 & 0.7 & 99.2 & - & - & - \\
\hline 20 & 4 & 0.5 & 99.7 & - & - & - \\
\hline 22 & 1 & 0.1 & 99.8 & 1 & 0.3 & 99.1 \\
\hline 25 & 1 & 0.1 & 99.9 & - & - & - \\
\hline 33 & 2 & 0.2 & 100.0 & - & - & - \\
\hline 38 & & & & 2 & 0.6 & 99.7 \\
\hline \multirow[t]{2}{*}{49} & & & & 1 & 0.3 & 100.0 \\
\hline & 826 & 100.0 & & 326 & 100.0 & \\
\hline
\end{tabular}

Notes and Sources: Sample of one seventh of all citations to Canadian economists 1970-76. Stratification achieved by use of list of names arranged in descending order of total citations received. For individuals ranked $1,8,15,22, \ldots$ the year 1970 was used. For those ranked 2, 9, 16, 23 ... the year 1971 was used, and so on for 7 years.

lag between completion and publication, leaving more time for them to be circulated in manuscript and for their contents to be discussed informally and at meetings of specialists.

The data of Table 5 imply that scientific knowledge in economics is subject to rapid obsolescence. One half of all references are to journal articles published less than 4.0 
years before and for the other forms of publication the figure is 2.6 years. Only about 10 per cent of all references are to works published more than 10 years before. Of course, the data refer to publications of only presently active Canadian economists, which sets an upper limit on the possible age of the citations in the sample. Perhaps this explains why the results differ from those found in some other studies. In a review of citation studies in different fields Broadus (1971) noted that in economics one analyst had found that 45 per cent of all citation were to works no older than 10 years while another found that 50 per cent were to works published within 6 years. Lovell (1973) found that in the year 1965, 46.5 per cent of citations in economics journals were to works published in the preceding five years.

It is possible to consider the age-profile of citations to the works of individual economists and departments and compare them with the norms presented in Table 5, though this is not done here. On the one hand one could argue that average ages of citations greater than the norm imply that an author has made contributions with a greater durability than average. This fact influences estimates of the quality of a person's life-time productivity. On the other hand, it is not certain that one can draw any particularly useful inferences about the relative productivity of two individuals with the same number of life-time citations to their work, if the average age of the citations of one is greater than that of the other. One simply may have produced more papers than the other, but by the criterion of citation counts assumed to measure influence as perceived by others, they have done equally well.

One question often raised in connection with citation counts is the frequency of selfcitations. In the sample under consideration there are 221 individuals, 50 or 23 per cent of which have one or more self-citations. As can be seen from Table 6, about 18 per cent of all citations are to own work on average, with a wide dispersion around this mean. Further analysis of self-citation frequencies shows that of the eleven individuals who owed 100 per cent of citations to themselves, 8 had only one citation altogether, one each had only two, three and seven. One person owed 17 out of 18 citations to his own publications. However, there does not seem to be any correlation between total citations and the frequency of self-citations. The observed behavior seems to be determined by personal preferences.

\section{JOURNALS OF PUBLICATION}

Table 7 shows the journals in which the 1502 publications of Canadian academic economists appeared during the period 1970-76. It comes as no surprise that the Canadian Journal of Economics contained 177 or 11.7 per cent and the French language Canadian L'Actualite Economique 91 or 6.1 per cent of all publications by Canadians. Surprising is, however, the large number of journals, 233, in which Canadians have published a mean of 6.45 articles. The distribution of articles per journal is quite skewed, with 66 journals having only one publication and the top 18 , or 7.7 per cent of all journals accounting for about 50 per cent of all publications.

The international nature of much of the work by Canadian economists is reflected in the fact that out of the top 29 journals only five are Canadian, two are published in Britain (Economica, Economic Journal), three in Continental Europe (Welwirtschaftliches Archiv, Kyklos and Etude Internationales), one in Australia (Economic Record) and the rest in the United States. Only three of the 29 journals have a French title, though some publish in both French and English, such as the Canadian Journal of Economics and 
Table 6

Self-Citation Percentages

\begin{tabular}{ccc}
$\begin{array}{c}\text { Percentages of } \\
\text { Self-Citations }\end{array}$ & Number of Individuals & $\begin{array}{c}\text { Total Sample } \\
\text { Self/Total Citations }\end{array}$ \\
\hline $10-19$ & 6 & $142 / 799=18$ percent \\
$20-29$ & 7 & \\
$30-39$ & 3 & 3 \\
$40-49$ & 5 \\
$50-59$ & 5 \\
$60-69$ & 1 \\
$70-79$ & 1 \\
$80-89$ & 1
\end{tabular}

Notes and Sources: sample of one seventh of all citations to Canadian economists 1970-76. Stratification achieved by use of list of names arranged in descending order of total citations received. For individuals ranked $1,8,15,22, \ldots$ the year 1970 was used. For those ranked 2, 9, 16, $23 \ldots$ the year 1971 was used, and so on for 7 years.

Kyklos. Finally, it should be noted that for unexplained reasons the journal Canadian Public Policy/Analyse de Politiques has not been covered by the SSCI since it commenced publication in Winter 1974. Since this journal has become an important publication outlet for Canadian economists, the analyses of journals as well as of citations and publications of individuals and departments above are not complete.

\section{CITATION AND PUBLICATION COUNTS FOR INDIVIDUALS}

For some purposes of analysis and policy it is useful to know the names of individuals who have received the largest number of citations and published the most journal articles. The names of Canadian economists with more than 100 citations during the period 1970 76 are shown in Table 8. Remarkable in this table is the dominance of persons from the University of British Columbia, which of course explains the institutions performance noted in Table 3.

Since there exists an often substantial lag between publications and their recognition through citations, highly productive individuals may not be found in Table 8 but could be expected to do so if a similar table were compiled in later years. Table 9 contains the names of persons who, during the period 1970-76 had at least 10 publications but fewer than 100 citations.

It should be noted that the rankings of individuals by citations is subject to the bias 


\begin{tabular}{|c|c|c|c|}
\hline \multirow[b]{2}{*}{ Rank } & & \multicolumn{2}{|c|}{ Publication } \\
\hline & & Number & Percent \\
\hline 1) & Canadian Journal of Economics & 177 & 11.7 \\
\hline 2) & L'Actualité Économique & 91 & 6.1 \\
\hline 3) & Econometrica & 66 & 4.4 \\
\hline 4) & American Economic Review & 56 & 3.7 \\
\hline 5) & Review of Economics and Statistics & 51 & 3.4 \\
\hline 6) & Industrial Relations Industrielle & 44 & 2.9 \\
\hline 7) & Journal of Political Economy & 40 & 2.7 \\
\hline \multirow[t]{2}{*}{ 8) } & Journal of Economic Inquiry (Western & & \\
\hline & Economic Journal) & 27 & 1.8 \\
\hline 9) & Journal of Finance & 25 & 1.6 \\
\hline 10) & Economica & 24 & 1.6 \\
\hline 11) & Canadian Pub1ic Administration & 24 & 1.6 \\
\hline 12) & Southern Economic Journal & 21 & 1.4 \\
\hline \multirow[t]{2}{*}{ 13) } & Journal of the American Statistical & & \\
\hline & Association & 21 & 1.4 \\
\hline 14) & Public Finance & 20 & 1. 3 \\
\hline 15) & Land Economics & 20 & 1.3 \\
\hline 16) & Journal of Regional Science & 18 & 1.2 \\
\hline 17) & Journal of Economic History & 16 & 1.1 \\
\hline 18) & Economic Record & 16 & 1.1 \\
\hline 19) & Quarterly Journal of Economics & 15 & 1.0 \\
\hline 20) & Economic Journal & 15 & 1.0 \\
\hline 21) & Journal of International Economics & 15 & 1.0 \\
\hline 22) & Weltwirtschaftiches Archiv & 14 & 0.9 \\
\hline 23) & American Journal of Agricultural Economics & 14 & 0.9 \\
\hline 24) & Kyklos & 14 & 0.9 \\
\hline 25) & Journal of Canadian Studies & 13 & 0.9 \\
\hline 26) & Economic Development and Cultural Change & 12 & 0.8 \\
\hline 27) & Industrial Relations & 11 & 0.7 \\
\hline 28) & Etudes Internationales & 11 & 0.7 \\
\hline 29) & Public Finance Quarterly & 11 & 0.7 \\
\hline
\end{tabular}

Frequencies for remaining journals:

Total number of Journals 233

Publications 1502
Number of Journals

3
5
11
3
10
13
17
22
30
66

66
Publications

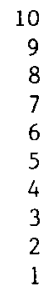

noted above and arising from the fact that references to publications with multiple authors are given only to the first-named author. While this bias, as well as clerical errors, tend to cancel in the calculation of university department means and medians, they may distort the rankings of persons in the last two tables. Therefore, in interpreting these tables, it may be safer to consider them to contain the names of groups of most widely cited and publishing individuals rather than a precise ranking. 
40 Herbert G. Grubel

Table 8

Individuals with over 100 Citations 1970-76

\begin{tabular}{|c|c|c|c|}
\hline \multirow[t]{2}{*}{ Name } & \multirow[t]{2}{*}{ University } & \multicolumn{2}{|c|}{ Number of } \\
\hline & & Citations & Publications \\
\hline Lipsey, R.G. & Queens & 474 & 6 \\
\hline Grubel, H.G. & SFU & 334 & 17 \\
\hline Laidler, D.E.W. & U. of W. Ontario & 200 & 10 \\
\hline Higgins, B.H. & Ottawa & 187 & 6 \\
\hline Archibald, G.C. & UBC & 172 & 5 \\
\hline Breton, A.A. & Toronto & 149 & 6 \\
\hline Marfels, C.T. & Dalhousie & 140 & 8 \\
\hline Helliwel1, J.F. & $\mathrm{LBC}$ & 138 & 11 \\
\hline Scoti, A.D. & $\mathrm{UBC}$ & 126 & 4 \\
\hline Dales, J.H. & Toronto & 120 & 2 \\
\hline Helleiner, $G$. & Toronto & 120 & 7 \\
\hline Cragg, J.G. & $\mathrm{UBC}$ & 115 & 11 \\
\hline Wannacott, R.J. & U. of W. Ontario & 111 & 2 \\
\hline Vandercamp, J . & Guelph & 110 & 5 \\
\hline Winch, D.M. & McMaster & 110 & 3 \\
\hline Melvin, J.R. & U. of W. Ontario & 108 & 12 \\
\hline Diewert, W.E. & $\mathrm{UBC}$ & 105 & 10 \\
\hline Bird, R.M. & Toronto & 103 & 9 \\
\hline
\end{tabular}

Surrce: Same as Table 1.

Tab1e 9

Individuals With More Than Nine Publications and Fewer Than 100 Citations 1970-76

\begin{tabular}{llcr}
\hline & University & \multicolumn{2}{c}{ Number of } \\
\cline { 3 - 4 } Name & Carleticition & 15 & 9 \\
\hline Maule, C.J. & Quebec a Itontreal & 12 & 18 \\
Chung, J.H. & Calgary & 11 & 9 \\
Adam, J. & Toronto & 11 & 13 \\
Casas, F.R. & U.W. Ontario & 11 & 5 \\
Palmer, J.P. & Toronto & 10 & 18 \\
Abouchar, A. & Montreal & 10 & 6 \\
Belanger, G. & & & \\
\hline
\end{tabular}

Source: Same as Table 1 


\section{SUMMARY AND CONCLUSIONS}

This paper has analysed the citation and publication counts of Canadian economists as a whole and grouped by individual departments, which may be useful in combination with other information about individuals in tenure and promotion decisions by departments and universities and in the allocation of resources among departments within and between universities. Of particular interest is the result that such a very large percentage of all economists appear to be concentrating their energies on teaching, synthesis and administration rather than publication. University administrators may find the information about department rankings useful in intra university resource allocation strategies. Sociologists and other specialists in organizational behavior may find the results worth attempts to explain differences in departments' productivity. Agencies and governments granting resources for research and the development of centers of excellence may add the information in this paper to their data on which they base their decisions. Undergraduate, graduate students and faculty members may wish to choose their universities of study or employment keeping in mind the results of this study. The data on journals of publication provide useful insights into the relative popularity and prestige of these publications outlets.

\section{FOOTNOTES}

1. See Part II below for a detailed description of this publication.

2. References to these letters and the papers prompting them are not shown in the bibliography appended to this paper. They can be found in the bibliography in the front of the annual volumes of the Social Science Citation Index.

3. Further analysis in this tradition is found in Bayer and Folger (1966); Margolis (1967); Cole and Cole (1967) and (1972); Garfield (1970) and (1979); Roche and Smith (1978); Miller and Tollison (1975); Hogan (1973); Siegfried (1972); and Dean (1976), the last four of which deal with departments of economics ranking using measures other than citations.

4. Since 1975 this list also indicates whom the author has cited in these publications. No use was made of this information, though it could serve as a base of studies of citation networks among Canadians and with foreign centers of learning.

5. Allison and Stewart, 1974 give reference to 8 studies that have found such skewness in the distribution for other scientific disciplines. They also report that in these studies citation counts are more skewed than publication counts, just as in the case of Canadian economists.

6. The result could also be due to the more rapid growth in the stock of publications by scientists who were more productive initially and did not enjoy any cumulative advantage through the reward system. This proposition is valid clearly for the life-time citations used in the study but may or may not be significant for the publication Ginis which are based on the record of the preceding 5 years.

\section{REFERENCES}

Aitchison, J. and J.A.C. Brown. The Lognormal Distribution. Cambridge: Cambridge University Press, 1957.

Allison, F.D. and J.A. Stewart.Productivity differences among scientists: Evidence for accumulative advan tage. American Sociological Review, 1974, 39, 4, 596-606.

American Economics Association, Handbook. Menasha, Wisc.: American Economics Association, 1974.

Bayer, A.E. and J. Folger. Some correlates of a citation measure of productivity in science. Sociology of Education, 1966, 39, 4, 381-390.

Billings, B.B. and G.J. Viksnins. The relative quality of economics journals: An alternative rating system. Western Economic Journal, 1972, 10, 4, 467-469.

Bordo, M.D. and D. Landau. The pattern of citations in economic theory 1945-68: Towards a quantitative history of economic thought. Carleton Economic Papers (mimeo), 1974-08. 
Broadus, R.N. The literature of the social sciences: A survey of citation studies. International Social Science Journal, 1971, 23, 2, 236-243.

Brookes, B.C. The growth, utility and obsolescence of scientific periodical literature. Journal of Documentation, 1970, 26, 4, 283-294.

Bush, W.C., P.W. Hammelman and J.R. Staff.A quality index of economics journals. Review of Economics and Statistics, 1974, 56, 1, 123-125.

Cartter, A.M. An Assessment of Quality in Graduate Education. Washington, D.C.: American Council on Education, 1966.

Cawkell, A.E. Science perceived through the science citation index. Endeavor, 1977, 1, 2, 57-62.

Clark, K.E. America's Psychologists: A Survey of a Growing Profession. Washington, D.C.: American Psychological Association, 1957.

Cole, J. and S. Cole The Ortega hypothesis: Citation analysis suggests that only a few scientists contribute to scientific progress. Science, $1972,178,368-374$.

Cole, S. and J.R. Cole Scientific output and recognition: A study in the operation of the reward system in science. American Sociological Review, 1967, 32, 3, 377-390.

Comfort, A. Pop charts for science. Nature, 1970, 227, 5262, 1069.

Dean, J.E. An alternative rating system for university economics departments. Economic Inquiry, $1976,14,1,146-153$.

De Solla Price, D.J, Little Science, Big Science. New York, N.Y.: Columbia University Press, 1963.

Dieks, D. and H. Chang. Differences in impact of scientific publications: Some indices derived for citation analysis. Social Studies of Science, 1976, 6, 2, 247-267.

Eagly, R.V. Economics journals as a communications network. Journal of Economic Lterature, 1975 , $13,3,878-888$.

Frankena, M. and K. Bhatia. Canadian contributors to economics journals 1968-72. Canadian Journal of Economics, 1973, 6, 1, 121-124.

Journal articles from Canadian economics departments, 1968-71. Western Economic Journal, 1972 , $10,3,352-353$.

Garfield, E. Citation analysis as a tool in journal evaluation. Science, 1972, 178, 4060, 471-479.

Citation indexing for studying science. Nature, 1970, 227, 669-671.

Citation Indexing: Its Theory and Application in Science, Technology and the Humanities. New York, N.Y.: J. Wiley and Sons, 1979.

Grubel, H.G. Citation counts for economists specializing in international economics: A tribute to the memory of Harry G. Johnson. Malayan Economic Review, 1980, forthcoming.

Citation counts for leading economists. Economic Notes, 1979, 8, 2, 134-145.

Hagstrom, W.O. Inputs, outputs and the prestige of American university science departments. Sociology of Education, 1971, 44, 4, 375-397.

Hansen, W.L. and B.A.W. Weisbrod. Towards a general theory of awards or do economists need a hall of fame. Journal of Political Economy, 1972, 80, 2, 422-431.

Hawkins, R.S., L.S. Ritter and I. Walter. What economists think of their journals. Journal of Political Economy, 81, 4, 1017-1032.

Hogan, T.D. Rankings of Ph.D. programs in economics and the relative publishing performance of their Ph.D.'s: The experience of the 1960's. Western Economic Journal, 1973, 11, 4, 429-450.

Institute for Scientific Information.Social Science Citation Index, annual volumes, available from 1970.

Kaplan, N. The norms of citation behavior: Prolegomena to the footnote. American Documentation, $16,179-185$.

Lotka, A.J. The frequency distribution of scientific productivity. Journal of the Washington Academy of Sciences, 1926, 16, 12, 317-323.

Lovell, M.C. The production of economic literature: An interpretation. Journal of Economic Literature, $1973,11,2,52-75$.

MacRae, D. Growth and decay curves in scientific citations. American Sociological Review, 1969, 34, $5,631-635$. 
Margolis, J. Citation indexing and the evaluation of scientific papers. Science, 1967, 155, 1213-1219.

Miller, J.C. and R.D. Tollinson. Rates of publication per faculty member in forty-five 'rated' economics departments. Economic Inquiry, 1975, 51, 4, 924-931.

Oppenheim, C. and S.P. Renn. Highly cited old papers and reasons why they continue to be cited. Journal of the American Society for Information Science, 1978, 29, 5, 225-231.

Quandt, R.E. Some quantitative aspects of the economics journal literature. Journal of Political Economy, 1976, 84, 4, 241-255.

Roche, T. and D.L. Smith. Frequency of citations as criterion for the ranking of departments, journals, and individuals. Sociological Enquiry, 1978, 48, 1, 49-57.

Siefgried, J.J. The publishing of economic papers and its impact on graduate faculty ratings, 1960-69. Journal of Economic Literature, 1972, 10, 1, 31-49.

Stigler, G.J. and C. Friedland. The citation practices of doctorates in economics. Journal of Political Economy, 1975, 83, 3, 477-507.

Wade, N. Citation analysis: A new tool for science administrators. Science, 1975, 188, 429-432. 